\title{
EL COMPROMISO PERIODÍSTICO, POLÍTICO, MILITAR Y ACADÉMICO SEGÚN ROBERT REDFORD
}

\section{THE JOURNALISTIC, POLITICAL, MILITARY AND ACADEMIC COMPROMISE AS ROBERT REDFORD}

Francisco Cabezuelo Lorenzo: Prof. Doctor Facultad de Humanidades y Comunicación. Universidad San Pablo - CEU. Madrid (España) francisco.cabezuelolorenzo@ceu.es

\section{CURRÍCULUM VITAE}

Doctor Europeo en 'Tecnologías, Estructuras y Tratamientos de la Información' por la Facultad de Ciencias de la Información de la Universidad Complutense de Madrid. Cuenta con diferentes postgrados universitarios realizados en diversas universidades europeas y norteamericanas. Es investigador activo del Grupo Europeo de Investigación MEDIADEM (Séptimo Programa Marco de I+D la Comisión Europea) a través de la Universidad de Castilla-La Mancha, del Grupo de Investigación en Formación Universitaria en Comunicación (GIFUCOM) en el Espacio Europeo de Educación Superior (EEES) de la Universitat Abat Oliba CEU de Barcelona y del Grupo de Investigación en EduComunicación (GIEC). Ha sido becario de postgrado de la Fundación "La Caixa" en las prestigiosas McGill University y Concordia University (Canadá) y de la Fundación Caja Madrid en The Queen's University of Belfast (Irlanda del Norte, Reino Unido). Igualmente, fue becario IES-UCM en la University of Saint Thomas en Minneapolis-Saint Paul (Estados Unidos). En su trayectoria profesional destacan numerosos puestos de responsabilidad como la dirección ejecutiva del Pabellón de la Santa Sede en la Exposición Internacional de 
Zaragoza 2008. Como periodista ha trabajado varios años en diferentes secciones de la agencia de noticias Europa Press, además de en diferentes emisoras de radio de ámbito estatal y en publicaciones de tirada nacional. En el campo de la comunicación institucional y las relaciones públicas ha desarrollado diferentes tareas en la Oficina del Parlamento Europeo en España y en el Departamento de Prensa del Senado. Ha sido profesor en la Facultad de Ciencias Humanas y de la Comunicación de la Universidad Europea Miguel de Cervantes de Valladolid (España) y en la Facultad de Ciencias de la Comunicación de la Universidad San Jorge de Zaragoza (España). En la actualidad es profesor de la Teoría de la Comunicación y de la Información en la Universidad CEU San Pablo en Madrid (España).

\section{RESUMEN}

A raíz del análisis de la película 'Leones por Corderos' (2007) del cineasta norteamericano Robert Redford, se pretende hacer una honda reflexión sobre la importancia del compromiso en la sociedad actual, con atención especial a la juventud y su falta de interés en los temas controvertidos, como por ejemplo la guerra de Afganistán. También analiza las relaciones entre los profesionales de la prensa y de la política, entre gobernantes y gobernados, entre leones y corderos.

\section{PALABRAS CLAVE}

Comunicación - Compromiso - Cine - Leones por corderos

\section{ABSTRACT}

Taking as a base the movie 'Lions for Lambs' (2007) directed by American film star Robert Redford, this articles tries to develop an in-depth analysis on the relevance 
and importance of commitment and engagement in current society. It pays special attention to youth and their lack of interest in controversial issues of today's world. As well, it analyses the relationship between press practitioners and politicians, between those who create the rules and those who follow them, between lions and lambs.

\section{KEY WORDS}

Communication - Commitment - Cinema - Lions for Lambs

\section{ÍNDICE}

1. Introducción: lecciones de cine

2. El estudio de 'Leones por corderos'

3. Una historia sobre la guerra alejada de las viejas batallitas

4. Varios relatos para una historia única

5. La obra en su contexto

6. El compromiso de los periodistas

7. El compromiso de los políticos

8. El compromiso desde el mundo académico

9. El compromiso militar

10. A modo de conclusión: lecciones para todos

11. Bibliografía y fuentes 


\section{TEXTO}

\section{Introducción: lecciones de cine}

Desde siempre, el cine ha sido inspirador de estudios, análisis, ensayos y reflexiones. Esta aportación es heredera de esta tradición. Desde que los hermanos Lumiére grabarán sus primeras imágenes, el cine subsiste como un objeto de estudio incierto y maleable (Fernández Labayen, 2008). El cine ha servido para acercarnos realidades desconocidas, para hacernos sentir experiencias que de otro modo jamás podríamos vivir ni sentir. El cine también se ha convertido en un elemento de denuncia social y política. El cine ha servido para representar mundos olvidados, marginados o ignorados.

Este artículo analiza esa realidad a través de una película actual que fue relativamente bien acogida en su momento por la crítica y por el público. ‘Leones por corderos' es un drama con una carga crítica y provocativa que estudia las consecuencias del compromiso. Nos relata las consecuencias de las decisiones políticas en la actividad militar y más en concreto en la vida de dos jóvenes militares estadounidenses en un conflicto tan real y actual como Afganistán.

Esta reflexión sobre la película 'Leones por corderos' quiere generar una reflexión sobre la realidad actual que vive nuestro mundo, caracterizado en estos días por una fuerte crisis económica, ligada a una fuerte crisis de valores y pérdida de fundamentos éticos traducidos en el pasotismo y relativismo de nuevas generaciones que huyen del compromiso y se escudan en excusas de lo más variado para luchar por un mundo mejor. Por este motivo, este análisis -al igual que la película- quiere reflexionar sobre el peso e importancia de la idea del 'compromiso' por parte de cada uno de nosotros desde nuestra postura como estudiantes, profesores, periodistas o 
militares. De este modo, este texto hace un análisis que tiene como fin intentar alcanzar una aproximación certera de la definición del concepto 'compromiso' en el campo de la Política, la Comunicación y la Universidad.

Todo este discurso se hilará a través del análisis de la película Lions for Lambs (Leones por corderos), dirigida en 2007 por el cineasta estadounidense Robert Redford y coprotagonizada por el propio Redford junto a sus compatriotas Meryl Streep y Tom Cruise. Muchas son las películas que nos han mostrado en la gran pantalla diferentes conflictos bélicos en los que ha quedado retratada la acción y valor de las Fuerzas Armadas, pero esta cinta no es una película bélica. Su género dramático lo sitúa junto a la denuncia social, en un ejemplo de cine de autor que reflexiona sobre el concepto de 'compromiso'. Hay numerosos ejemplos tanto en el cine norteamericano como en el europeo sobre esta temática. Pero, pocas producciones tratan con tanta profundidad, seriedad y respeto la idea del 'compromiso' como este título. Huyendo de efectos especiales y espectaculares imágenes y escenarios bélicos -que también los hay-, esta película intenta hacer hincapié en las razones personales y humanas que mueven a los soldados a llegar a dar su vida por unos ideales y una bandera.

\section{El estudio de 'Leones por corderos'}

A través de un pormenorizado análisis de contenido, esta investigación inédita analizará la representación audiovisual de las Fuerzas Armadas de los Estados Unidos de América. En un principio, analizará la imagen de los militares norteamericanos en el conflicto afgano, pero lo hará siempre sabiendo que hay cosas en común entre los militares estadounidenses y del resto del mundo occidental. Igualmente, el análisis prestará en todo momento una atención especial a la idea de 'compromiso', entendiéndola como idea-fuerza motor de toda la película. Este 
compromiso militar será comparado con el compromiso político, interpretado por Tom Cruise, el compromiso periodístico por descubrir la verdad y transmitirla a través de los medios de comunicación, que es el rol de Meryl Streep como periodista, o a través de la universidad, que es el papel que interpreta el propio Robert Redford en su rol de profesor universitario. La metodología clásica a la hora de analizar películas se ha basado en tres modelos como son las teorías de la enunciación, del canal y de la recepción. Sabiendo que en el fondo son complementarias, esta investigación las entrecruza, y desde la honestidad huye de metodologías que encorseten el estudio más allá de lo necesario. De este modo, esta investigación busca: hacer un mapa conceptual que refleje el contenido temático de la película, reflexionar sobre las ideas principales, acotar la idea central que se pretende transmitir, y, finalmente, expresar cómo han influido, reforzando o limitando, los elementos técnicos con el fin de presentar la idea central.

Este análisis cuenta con una formulación híbrida y nada purista. Parte de la idea generalmente aceptada de que el cine es un fenómeno en evolución, una realidad cambiante. Esta constante evaluación del cine y sus múltiples -aunque tradicionales formatos- han dado como fruto una gran riqueza en el lenguaje fílmico. Y, por tanto, en las diferentes técnicas del análisis de la narrativa cinematográfica. De este modo, los diferentes estudios sobre el cine, teorías del cine y corrientes de análisis se han visto influenciados por esta mutabilidad. El cine es un fenómeno complejo. Como en la mayoría de las ciencias sociales, cualquier intento por reducir esta complejidad y llegar a una definición unívoca y totalizadora está condenada al fracaso (Fernández Labayen, 2008). 


\section{Una historia sobre la guerra alejada de las viejas batallitas}

Desde sus orígenes, el cine ha reflejado conflictos armados reales y ficticios. Sin embargo, 'Leones por corderos' no es una cinta tradicional de cine bélico. El film es una reflexión con argumentos, a veces fríos y otras veces emotivos, sobre el auténtico tejido social del día a día de Estados Unidos, en particular, y del mundo occidental, por extensión. La película cuenta las historias de gente de diferentes estratos sociales, desde senadores a jóvenes de barrios populares, que sienten el compromiso por hacer de su país y del planeta un mundo mejor. En el fondo, en las películas de Robert Redford siempre ha aparecido esta preocupación. De hecho, para algunos críticos, este hilo conductor es el que ha tejido la totalidad de su colorida y variopinta carrera, tanto como artista bohemio en sus orígenes, como estrella de éxito, como galán de Hollywood o como paladín del movimiento del cine independiente.

Otro de los aspectos que es preciso comentar de esta película es su título tan peculiar y traducido fielmente del original inglés, 'Lions for Lambs' a 'Leones por Corderos' en español. El título sale de una escena en la que Redfrod en su papel de profesor Malley ataca la apatía del público norteamericano -en especial de los jóvenes- hacia los grandes retos del mundo actual y, de manera específica, el pasotismo de algunos respecto a graves problemas como el terrorismo mundial. El doctor Malley argumenta "el problema no es con la gente que inició esto". "El problema es de todos nosotros que no hacemos nada", añade. De este modo, trata de iluminar a un prometedor pero indiferente estudiante acerca de su propia responsabilidad y función en el mundo respecto a temas candentes y de actualidad. Del mismo modo, es una crítica a los altos mandos responsables de la Defensa de Estados Unidos, que están dispuestos a pagar el precio de esa guerra utilizando la vida de los soldados jóvenes dispuestos a darlo todo por EEUU y un mundo sin terrorismo. Con el fin hacerle entender esta situación, se remonta a la I Guerra Mundial y le pone un 
ejemplo. Miles de soldados británicos murieron en un inútil ataque en contra de soldados alemanes que se hallaban bien atrincherados. Los soldados alemanes llegaron a admirar tanto a sus contrapartes que escribieron poemas é historias alabando su heroísmo. También criticaron la arrogante incompetencia de los oficiales del Ejército Británico quienes, desde la seguridad de la retaguardia, tomaban el té mientras los jóvenes eran sacrificados de manera inútil. De ahí, surge la frase de los alemanes que sirve para titular la cinta. "Ich habe noch nie solchen lowen gesehen die solche lamer gefuhrt werden" era la cita original alemana. "En ningún lugar he visto a tales leones conducidos por tales corderos", diríamos en español.

\section{Varios relatos para una historia única}

El autor del guión de la película es el norteamericano Matthew Michael Carnahan, guionista también de 'La sombra del poder' (State of Play) de 2009 protagonizada por Russell Crowe y Ben Affleck. Según la prensa, Robert Redford, que además de director es el productor de la cinta, y que llevaba siete años sin dirigir, desde que se pusiera detrás de las cámaras para filmar 'La leyenda de Bagger Vance' en el año 2000, cuando llegó a sus manos el guión del Carnahan, inmediatamente se sintió interesado por el proyecto y tuvo muy buenas sensaciones sobre el mismo. "Apareció de forma inesperada. Me sorprendió porque era político y porque hay tanta inseguridad comercial en el cine en los tiempos que corren, que parece que sólo los que son seguros llegan a rodarse. Los que son de naturaleza más arriesgada, los que quizá le hagan a uno pensar o plantearse preguntas, son más difíciles de hallar. Y sin embargo, ésas son las películas que siempre he disfrutado rodando", afirmaba Redford en una entrevista a la prensa norteamericana.

La cinta cuenta a través de tres relatos la historia de dos estudiantes de la West Coast University (California), el afroamericano Arian Finch (interpretado por Derek Luke) 
y el estadounidense de origen mexicano Ernest Rodríguez (Michael Peña), de orígenes humildes que con el fin de labrarse un futuro mejor se alistan en el Ejército de los Estados Unidos y terminan en Afganistán en plena guerra contra el régimen talibán. Ambos fueron alumnos del profesor Sthepen Malley (Robert Redford). La historia es vista desde tres puntos de vista diferentes.

En primer lugar, se cuenta la historia de forma directa de los dos jóvenes en tierras afganas. En segundo lugar, el profesor Malley cuenta la historia de Ernest y Arian a otro alumno más joven, a Todd Hayes (interpretado por Andrew Garfield) al que Malley llama a su despacho para una tutoría con el fin de hacerle ver que no está aprovechando ni su juventud ni su talento con sus continuas faltas de asistencia a clase. Y, finalmente, en tercer lugar, se cuenta la historia de Ernest y Arian a través de la entrevista que en esos momentos se está celebrando en Washington D.C. entre el senador Jasper Irving (papel interpretado por Tom Cruise) y la periodista Janine Roth (interpretada por Meryl Streep). El político, joven promesa republicana y posible candidato, con una gran formación militar y universitaria que aspiraba a algún día a la Casa Blanca, llama a la periodista de televisión de izquierdas que ansía su jubilación, para darle una exclusiva: su nueva estrategia militar para vencer al régimen talibán. Desde California y desde la capital federal se narra la historia que está ocurriendo de forma paralela en Afganistán. De este modo, mientras Arian y Ernest luchan por sobrevivir en Asia, su historia se convierte en el hilo que une dos relatos diferentes en dos puntos bastante distantes de Norteamérica. Toda la narración se entrecruza hasta darnos cuenta de que son una misma historia y suponen una reflexión y un reflejo la sociedad occidental actual, representada en la sociedad norteamericana y sus complejas relaciones con el resto del planeta.

Al mismo tiempo, el film critica y denuncia una sociedad débil, floja en sus compromisos, una juventud hedonista, que rehúye el esfuerzo y el sacrificio, una 
sociedad que a través de los medios de comunicación pone su lupa y centra su tiempo en tonterías sin sentido. A través de pequeños detalles y ciertas imágenes que no dejan indiferente a nadie, especialmente al final de la película, cuando el joven Todd tras su entrevista con el profesor Malley, vuelve con los compañeros de su fraternidad universitaria, cuya sala principal está presidida por una pantalla gigante televisión con tres grandes consolas de videojuegos en su parte superior, en las que tras un estúpido espacio sobre últimas tendencias en maquillaje femenino, al cambiar de canal aparece la presentadora Summer Hernández-Kowalski comentando las imágenes de una noticia del corazón sobre una famosilla al más puro estilo Britney Spears, noticia que al parecer interesa más que la nueva estrategia militar en Afganistán, que en primicia el senador Irving cuenta a Janine Roth y que aparece por abajo en subtítulos, mientras la película llega a su fin.

"Yo esperaba que esta película provocara a los espectadores a contemplar dónde estamos en este país y como llegamos hasta aquí", afirmaba el director en una entrevista en el momento del lanzamiento comercial de la película. "Para mí, el guión trata de mucho más que los problemas de los que somos testigos ahora mismo. En realidad, se trata de los factores más profundos que yacen bajo dichos problemas, y que ahora están siendo experimentados personalmente por personas auténticas", concluía Robert Redford.

\section{La obra en su contexto}

La película fue presentada a los medios en el Festival de Cine de Londres, el 22 de octubre de 2007, y a partir de ahí se proyectó en las pantallas de un total de 47 países durante todo el otoño e invierno. En España, se estrenó el 9 de noviembre de 2007. La película, grabada ese mismo año, cuenta una historia tan real y contemporánea como es la guerra de Afganistán. Este conflicto bélico tiene antecedentes históricos en la 
Guerra Fría, en la que el pueblo afgano luchaba contra la Unión de Repúblicas Soviéticas Socialistas (URSS), con ayuda de Estados Unidos. Esta paradoja, como comenta la película, hace que los Estados Unidos estén luchando hoy contra un enemigo al que ellos facilitaron en los años ochenta las armas con las que hoy luchan.

La actual guerra es fruto de los ataques terroristas del 11 de septiembre de 2001 cometidos por Al-Qaeda contra Occidente, en general, y Estados Unidos, en concreto, cuando estrellaron los aviones llenos de pasajeros contra el Pentágono y las Torres Gemelas del World Trade Center en Nueva York. Como consecuencia, EEUU puso en marcha la denominada 'Operación Libertad Duradera' el siete de octubre de 2001. La OTAN y Naciones Unidas apoyaron la iniciativa contra el régimen talibán, que en un principio fue expulsado del poder.

Con el tiempo, sin embargo, no se ha logrado sembrar la estabilidad en el país. Desde 2006, se ve amenazada la estabilidad como resultado de la fragilidad del gobierno de Kabul, presidido por Hamid Karzai, su poco peso fuera de la capital, el incremento de la actividad terrorista, la producción de drogas en las zonas rurales, imposibles de controlar. A todo ello, se ha sumado la imposibilidad de implantar modelos democráticos en el país. En noviembre de 2009, el líder opositor Abdulá Abdulá acaba de anunciar su renuncia a presentarse a la segunda vuelta de las elecciones que debían celebrarse el ocho de noviembre, lo cual supuso la reelección automática del actual presidente Karzai.

\section{El compromiso de los periodistas}

Los diferentes personajes de la película, la periodista, los mandos militares o los jóvenes muestran cada uno de ellos su visión del concepto compromiso. "Creo que es una película acerca de la responsabilidad personal, acerca de jóvenes que aceptan el 
papel que desempeñan a la hora de dar forma al futuro, y acerca de la forma como cada uno de nosotros resuelve las opciones que ha de tomar a lo largo de la vida a fin de intentar que este mundo sea mejor". Sin duda alguna, desde el punto de vista de los estudios en Comunicación Social, la cuestión del compromiso periodístico es uno de los aspectos más interesantes y propicios para la reflexión y el debate. En la actualidad, tal y como lo define Juan Varela (2009) estamos sufriendo “el periodismo figurante". Se refiere al periodismo no participativo, en el que el periodista es un mero transmisor del poder y al que se le da una supuesta noticia para que la repita como un papagayo o se le invita a una rueda de prensa en la que luego no se le deja hacer preguntas.

Lamentablemente, esta situación viene siendo muy común últimamente en nuestro país. “Otra vez el periodismo figurante nuestro de todos los días. Otra vez la letanía de lamentos. Otra vez la pasividad y la hipocresía de quejarse como viejas asustadas y no tener el coraje suficiente para plantar cara a una clase política irresponsable y abonada a una democracia escénica sin compromiso" (Varela, 2009). Pero, ¿cuál es ese compromiso del periodista en una democracia contemporánea al estilo occidental. La profesora María Teresa La Porte (2004) la resume de esta manera: el periodista debe difundir la verdadera información con la intención de generar una verdadera convivencia participativa, libre y responsable, sin miedo a los castigos del mercado ni del Estado, por fines loables que no atiendan exclusivamente a la primicia o al número de ventas.

En 'Leones por corderos', Meryl Streep en su papel de la reportera Janine Roth protagoniza varias escenas en las que refleja su insistente deseo por saber toda la verdad. En un momento determinado de la película, tiene lugar esta escena que muestra esta lucha por la verdad. “¿Por qué hemos enviado 150.000 soldados a Irak, que no nos atacó, y tan sólo la décima parte al país que sí nos atacó?", pregunta la 
periodista. "¿Hasta cuándo van a estar haciendo esa pregunta?", responde el senador. “¡Hasta que nos den una respuesta!”, zanja contundentemente la periodista. Esta determinación, sin embargo, no llega hasta sus últimas consecuencias, al final de la película, la periodista con una dilatada carrera, al borde de los 58 años de edad y con 40 años de experiencia como periodista a sus espaldas, con una madre mayor enferma que necesita cuidado 24 horas al día, se ve en la obligación de acatar todas las órdenes de su jefe de redacción y cumplir con las pautas de su cadena de televisión, más interesada en contenidos vacíos, huecos, comerciales y carentes de 'compromiso social'. La periodista que se enfrenta al senador y a su editor porque no quiere ser una mera pieza en el engranaje de la transmisión de noticias del poder a la sociedad a través de la televisión, termina cediendo y publicando la exclusiva que le ha dado el senador, aunque no crea en ella, ni haya podido corroborarla por otras vías o con otras fuentes.

volver al sexto apartado volver al principio del artículo volver al principio

\section{El compromiso de los políticos}

Del mismo modo que la película critica el rol de la prensa en nuestros días, también intenta retratar a la clase política actual, preocupadísima por los estudios de opinión, los sondeos, pruebas de telegenia y carrera interna de los partidos por el poder y el liderazgo. En teoría, el compromiso político hoy en día debe estar basado en el servicio público, del que son responsables desde el momento en el que son elegidos. Por tanto tienen una función de representación, pero su misión va más allá. Consiste también en implementar un programa y unos ideales por los que han sido elegidos, por tanto, se les pide también que ofrezcan propuestas y cumplan lo prometido. Como afirma Zúñiga (2002), "en la existencia y misión de los partidos políticos encuentra el pueblo soberano su gran instrumento o auxiliar para que la delegación 
de los poderes sea efectiva. El partido político es el intermediario entre el soberano y los órganos del Estado".

En el caso de 'Leones por corderos', la figura del político está representada por el senador republicano Jasper Irving, número uno de su promoción en la Academia Militar de Westpoint y graduado por la Universidad de Harvard. Irving es la imagen del político joven, bien formado, leal al partido, con ganas de demostrar su valor, por tanto con ambiciones. Al mismo tiempo, lejos de estereotipos, muestra su compromiso con la sociedad americana de diferentes modos. Una escena en la que se pone de manifiesto este compromiso es en la entrevista con la periodista. "Es mi responsabilidad, es parte de las obligaciones de mi trabajo proteger al pueblo americano y ése es el motivo por el que ponemos en marcha esta nueva estrategia militar", afirma el senador. “¿Cuándo empezará esta estrategia?”, añade la periodista. "Hace diez minutos", responde el político.

Éste es otro ejemplo de la determinación política reflejada en la película. El político debe tomar decisiones más allá de la popularidad de las mismas si estima que servirán para resolver un problema o evitar males mayores. Esta misma realidad se manifiesta también en otra escena. “Esta estrategia hará que podamos enfrentarnos, luchar y matar a nuestros enemigos, lo que ayudará a la reconstrucción del país. Y si nos lleva diez años, diez años estaremos allí. Cueste lo que cueste". La determinación es también un elemento clave del compromiso militar y político.

\section{El compromiso desde el mundo académico}

Junto a la pugna dialéctica entre la periodista y el senador, la película nos ofrece el enfrentamiento verbal entre el profesor universitario y su alumno, donde uno al otro se lanzan mutuas acusaciones. “Aquellos que no saben y no son capaces de hacer una 
cosa, sin embargo, enseñan cómo hacerlas", acusa el joven alumno a su viejo profesor de Ciencia Política. Del mismo modo, el joven alumno Todd Hayes afirma que profesores y políticos tienen una cosa en común: "nunca dicen nada aunque no paren de hablar". Pero, ¿en qué consiste el compromiso y la obligación real de un profesor con su alumno? Son varias las obligaciones del profesor: transmitir conocimiento, generar saber, despertar el interés por la ciencia y la cultura.

Para el doctor Malley, sobre todo, un profesor es un "vendedor". "Los profesores somos vendedores. Os vendemos a vosotros mismos", afirma. ¿Qué quiere decir con esto? La obligación de un profesor consiste en sacar lo mejor de sus alumnos, explotar su potenciar y ponerles un espejo delante de sí mismos para que mejoren, para que den lo mejor de cada uno de ellos en cada uno de sus actos. Su obligación consiste en hacerles despertar del letargo, vencer su pereza e inmovilidad. Hay que hacerles sentirse útiles en esta sociedad y ayudarles a encontrar su camino en el mundo.

"Es mejor intentarlo y fracasar que no intentarlo", afirma Malley, que anima al joven Todd a participar, estudiar más, asistir a todas las clases y abandonar el pasotismo en el que está instalado, víctima de la desilusión y de la falta de motivación. "Las decisiones que tomes ahora no podrán cambiarse en un futuro con facilidad. Y con el paso del tiempo dejarás de ser quien has sido y serás una persona diferente", le dice el profesor. "Eres un adulto. Lo malo de ser adulto es que empieza antes de que te des cuenta. En estos momentos ya has tomado más de una docena de decisiones (...) Las decisiones que tomes ahora son tu responsabilidad para siempre y de nadie más", concluye Malley en un intento por hacer que el joven madure y se haga responsable de sus actos.

volver al octavo apartado volver al principio del artículo volver al principio 


\section{El compromiso militar}

¿Qué compromiso más grande puede existir que merezca dar la vida a cambio? ¿Qué entrega es mayor que dar la propia vida por unos ideales, por un país y por un futuro mejor? Este es el compromiso representado en la película por los jóvenes soldados Arian Finch y Ernest Rodríguez. Han aprendido de su adolescencia en los barrios periféricos más duros de Estados Unidos que sobrevivir no es fácil y que hay que luchar por conseguir una vida mejor, hay que estudiar, hay que esforzarse y, si es preciso, hay que comprometerse. Por esto motivo, Arian y Ernest, en clase proponen en una lección sobre Relaciones Internacionales una política de compromiso no sólo para el Gobierno, también para sus ciudadanos. Ellos creen firmemente en esto, por lo que anuncian su intención de alistarse en el Ejército de los Estados Unidos. Y así marchan a Afganistán, con el deseo de volver convertidos en héroes y con una vida mejor tras su esfuerzo.

Triste y lamentablemente, nunca volverán. Morirán abatidos por los terroristas en las frías y nevadas montañas afganas. Mueren en el intento frustrado de poner en marcha una nueva estrategia militar creada en Washington con intereses políticos (aumentar la popularidad de un presidente y animar a la opinión pública) y alejada de los riesgos que conlleva para sus propios militares destacados sobre el terreno. Arian y Ernest mueren como leones, con valor, de pie, luchando, víctimas de los terroristas, pero al mismo tiempo, en una situación provocada por los corderos de Washington, que no han calculado los riesgos de la operación.

El joven afroamericano Arian Finch y el mexicano Ernest Rodríguez pierden su vida de la misma manera que ya lo hicieron en la I Guerra Mundial miles de soldados británicos. Con la expresión 'leones por corderos' los alemanes retrataron la incompetencia de los oficiales del Ejército Británico quienes, desde la seguridad de la 
retaguardia, tomaban el té mientras los jóvenes eran sacrificados de manera inútil. De ahí, surge la frase de los alemanes que sirve para titular la cinta. La mayor parte de los expertos están de acuerdo que esa fue expresión tiene su origen en la Batalla del Somme, uno de los encuentros más sangrientos en la historia de la guerra moderna. Mientras que algunos historiadores militares acreditan como autor a un infante anónimo, otros arguyen que la fuente no es otro que el General Max von Gallwitz, el Comandante Supremo de las Fuerzas Alemanas.

La Batalla del Somme empezó en Julio de 1916. Un avance masivo de los Aliados en el Frente Oeste se detuvo cerca del río Somme en el Norte de Francia y sufrió un destino pasmoso. Las tropas atrincheradas y bien armadas del Káiser Guillermo II arrasaron con 58.000 soldados británicos, una tercera parte de ellos en el primer día de batalla. La cifra aún se mantiene como la más alta para un solo día de batalla. El desastroso ataque finalmente fue cancelado en noviembre. Después de una campaña de cinco meses, los Aliados habían avanzado sólo doce kilómetros con un coste de 420.000 bajas británicas además de 200.000 bajas francesas adicionales.

No es la primera vez que esta expresión aparece ligada al cine. En la I Guerra Mundial, se empezaron a filmar las guerras. Los largos meses de la sangrienta lucha fueron capturados por cámaras de cine y lanzados posteriormente en todo el Reino Unido como una película de propaganda bélica bajo el título de 'La batalla del Somme'. Encontramos así, uno de los primeros ejemplos del siglo XX en el que los civiles en el frente doméstico fueron expuestos a los horrores de la guerra.

Las críticas aparecen divididas respecto a la visión del Ejército que se ofrece en la película. Algunos consideran que el film es una película típicamente americana en la que los soldados siempre son héroes y mueren como tales, por defender su país, sus libertades y su bandera. Sin embargo, la cinta fue seriamente criticada e incluso 
boicoteada en Estados Unidos, donde algunos medios y críticos dieron la espalda desde el principio a los argumentos de Robert Redford.

Parece ser que el simple hecho de hacer una película sobre un conflicto actual, todavía sin resolver, y que duele en la sociedad americana contribuyó a frenar la promoción de la película, que sin embargo, reconociendo que no es una película para todo tipo de espectadores, no deja de ser muy recomendable e interesante. Es sobre todo una cinta generadora de debate sobre cuestiones éticas y sociales y tiene una capacidad inmensa para hacernos reflexionar sobre nuestras actuaciones entendidas como constructoras de la realidad actual que nos rodea.

\section{A modo de conclusión: lecciones para todos}

Robert Redford, el que fuera pensador alternativo y bohemio en los años sesenta del siglo pasado en sus viajes y estancias por Europa, comprometido siempre socialmente, lanza varios mensajes en 'Leones por Corderos'. Alejado de la demagogia y de los tópicos, el director rinde homenaje a aquellos soldados que dan su vida por América, al tiempo que nos hace varias preguntas y perfila algunas respuestas. Para algunos críticos, Robert Redford hace las preguntas y también da las respuestas sin que quede lugar a la discusión: el Gobierno de Estados Unidos busca réditos electorales y miente respecto a la guerra en Afganistán, mientras que los periodistas, y medios de comunicación por extensión, son corresponsables de la reproducción de estos intereses y hasta falacias en algunos casos. A la vez, el director critica a la gran mayoría de la actual juventud que parece pasar de todo. Por el contrario, aquellos que sí se comprometen y no son víctimas del pasotismo y la desgana, a pesar de sus esfuerzos, son los que pagan los platos rotos. Los soldados de a pie que en su mayor parte forman parte de minorías raciales y salen de barrios 
desfavorecidos son los que terminan dando la vida por los políticos de Washington y sus compatriotas.

Este sentimiento de respeto y homenaje a todos los caídos se ve en la que es probablemente- el momento más bello, emotivo y significativo de toda la película: la escena final que resume un sentimiento y en la que Meryl Streep contempla el pasado y el presente de su país a través de la ventana de un taxi que recorre las calles de la capital federal paseando frente a los numerosos monumentos, cementerios y homenajes a los militares fallecidos.

\section{Bibliografía y Fuentes}

BERGANZA CONDE, M. R. \& RUIZ SAN ROMÁN, J. A.: "Investigar en Comunicación. Guía práctica de métodos y técnicas de investigación social en Comunicación". McGraw Hill. Madrid, 2005.

CABEZUELO LORENZO, Francisco: "La reconstrucción de los modelos de belleza americana de los años sesenta en Mad Men". I Congreso Internacional de Estética Cinematográfica 'La ilusión de la belleza'. Bilbao. Universidad del País Vasco-Euskal Herriko Unibersitatea, 2009.

CASETTI, Francesco: " Teorías del cine". Cátedra, Madrid, 1994.

CUEVAS ÁLVAREZ, Efrén: "La narratología audiovisual como metodología". Portal de la Comunicación. Institut de la Comunicació-Universitat Autònoma de Barcelona, 2009. 
FERNÁNDEZ LABAYEN, Miguel: "Pensar el cine: un repaso histórico a las teorías cinematográficas". Portal de la Comunicación. Institut de la Comunicació-Universitat Autònoma de Barcelona, 2008

INTERNET MOVIE DATABASE (IMDB). www.imdb.com

LA PORTE, María Teresa. "El compromiso social del periodista". Actas del II Simposio San Josemaría y la Comunicación. Universidad de Navarra. Disponible en www.simposiosanjosemaria.com/actas.

ORTEGA Y GASSET, José: "Misión de la Universidad". Madrid, 1930. Edición del profesor Raúl J. A. Palma (2001), Buenos Aires. Disponible online en: www.cedus.cl

REDFORD, Robert: Leones por Corderos (Lions for Lambs). Metro Goldwyn Meyer-Twentieht Century Fox, 2007.

VARELA, Julio: "Compromiso contra la manipulación". 2009. Blog Periodistas 21.http:/ / periodistas21.blogspot.com/2009/08/compromiso-contra-lamanipulacion.html

ZÚÑIGA GUARDIA, Carlos Iván: "La alta misión de los partidos políticos". Diario 'La Prensa' (22/06/2002). Ciudad de Panamá, 2002. Disponible en http://mensual.prensa.com/mensual/contenido/2002/06/22/hoy/opinion/604432 .html 